\title{
Erythropoietin reduces the expression of myostatin in mdx dystrophic mice
}

\author{
D. Feder ${ }^{1}$, M. Rugollini ${ }^{1}$, A. Santomauro Jr. ${ }^{1}$, L.P. Oliveira ${ }^{1}$, V.P. Lioi ${ }^{1}$, R. dos Santos ${ }^{2}$ \\ L.G. Ferreira ${ }^{2}$, M.T. Nunes ${ }^{2}$, M.H. Carvalho ${ }^{2}$, P.O. Delgado ${ }^{1}$, A.A.S. Carvalho ${ }^{1}$ and F.L.A. Fonseca ${ }^{1,3}$ \\ ${ }^{1}$ Faculdade de Medicina do ABC, Santo André, SP, Brasil \\ ${ }^{2}$ Instituto de Ciências Biomédicas, Universidade de São Paulo, São Paulo, SP, Brasil \\ ${ }^{3}$ Instituto de Ciências Químicas, Ambientais e Farmacêuticas, Universidade Federal de São Paulo, Diadema, SP, Brasil
}

\begin{abstract}
Erythropoietin (EPO) has been well characterized as a renal glycoprotein hormone regulating red blood cell production by inhibiting apoptosis of erythrocyte progenitors in hematopoietic tissues. EPO exerts regulatory effects in cardiac and skeletal muscles. Duchenne muscular dystrophy is a lethal degenerative disorder of skeletal and cardiac muscle. In this study, we tested the possible therapeutic beneficial effect of recombinant EPO (rhEPO) in dystrophic muscles in mdx mice. Total strength was measured using a force transducer coupled to a computer. Gene expression for myostatin, transforming growth factor- $\beta 1$ (TGF- $\beta 1$ ), and tumor necrosis factor $\alpha$ (TNF- $\alpha$ ) was determined by quantitative real time polymerase chain reaction. Myostatin expression was significantly decreased in quadriceps from $\mathrm{mdx}$ mice treated with rhEPO (rhEPO $=0.60 \pm 0.11$, control $=1.07 \pm 0.11$ ). On the other hand, rhEPO had no significant effect on the expression of TGF- $\beta 1$ (rhEPO $=0.95 \pm 0.14$, control $=1.05 \pm 0.16$ ) and TNF- $\alpha$ $($ rhEPO $=0.73 \pm 0.20$, control $=1.01 \pm 0.09)$. These results may help to clarify some of the direct actions of EPO on skeletal muscle.
\end{abstract}

Key words: Muscular dystrophy; Erythropoietin; Myostatin; Skeletal muscle; Quadriceps

\section{Introduction}

Erythropoietin (EPO) has been well characterized as a renal glycoprotein hormone regulating red blood cell production by inhibiting apoptosis of erythrocyte progenitors in hematopoietic tissues (1). EPO receptors have been described in many different cells and tissues, including muscle, neurons, astrocytes, microglia, developing heart, cancer cell lines, Leydig cells, and gastric mucosal cells, suggesting other actions of this hormone (2). Indeed, many of these tissues are responsive to stimulation with recombinant human EPO (rhEPO) (2). The relationship between EPO receptors and skeletal muscle has been poorly investigated. It has recently been reported that EPO exerts regulatory effects on both cardiac and skeletal muscle (3).

Because mouse myoblasts express EPO receptors, administration of EPO can stimulate proliferation of myoblasts to expand the progenitor population during differentiation, resulting in a potential role in muscle development or repair (4). Mice lacking EPO or its receptors suffer from heart hypoplasia and have a reduced number of proliferating cardiac myocytes (5).

The effects of EPO on muscle cells have also attracted the attention of athletes. Because EPO increases red blood cell mass and exercise capacity in anemic patients, it might have the same effect in an athlete's body, thereby enhancing performance (6). In addition to the hematopoietic effects, EPO is capable of promoting angiogenesis in muscle cells (7), providing an additional route to increase the supply of oxygen to the working muscles. Furthermore, the possible involvement of EPO in muscle repair processes (4) can imply that athletes who abuse rhEPO have healthier muscles. With this reasoning, athletes began using rhEPO, and thus rhEPO has been on the International Olympic Committee's list of banned substances since 1990 (6).

Duchenne muscular dystrophy (DMD) is a lethal degenerative disorder of skeletal and cardiac muscles that affects 1 in 3500 male births (8). DMD patients characteristically display progressive muscle weakness, which begins in early childhood (9). Although DMD is present at birth, clinical symptoms are not evident until 3-5 years of age (10). Initial symptoms include leg weakness and increasing convex curvature of the spine muscles and results in progressive weakness, usually leaving DMD patients wheelchair bound by age 11 or 12 years (11).

Correspondence: D. Feder, Faculdade de Medicina do ABC, Avenida Príncipe de Gales, 821, 09060-650 Santo André, SP, Brasil. E-mail: feder2005@gmail.com 
Affected individuals usually die due to respiratory or cardiac insufficiency by the second or third decade of life (12). So far, the only pharmacological treatment proven to be effective for DMD is steroids (13).

Dystrophin is considered a key structural element in muscle fiber, and the primary function of the dystrophinassociated protein complex is to stabilize the plasma membrane. The absence of dystrophin is followed by a sequence of events such as calcium influx, reactive oxygen species activity, and inflammation, leading to muscle injury (14).

This study tested the possible beneficial effect of recombinant EPO therapy in the degenerative process of dystrophic muscles in mdx mice. The absence of dystrophin in these mice produces a phenotype quite different from that of dystrophin deficiency in humans. Under normal conditions, mdx mice show little overt symptoms of weakness, but, if forced to engage, they show more pathological changes than when resting (15).

\section{Material and Methods}

Male mdx mice were maintained in the experimental laboratory of $A B C$ Faculty of Medicine (FMABC) at constant temperature $\left(20^{\circ} \mathrm{C}\right)$, with a $12: 12$-h light-dark cycle, and received diet and water ad libitum. The mice weighed 25$30 \mathrm{~g}$. All procedures were conducted in accordance with the Declaration of Helsinki and the Guide for the Care and Use of Laboratory Animals, and were approved by the Ethics Committee of Faculdade de Medicina do ABC in 2006 (Protocol: \#04/2006).

The experimental groups were as follows: $7 \mathrm{mdx}$ mice were injected with rhEPO (1000 IU/kg ip) 3 times per week and $6 \mathrm{mdx}$ mice received saline. All animals were submitted to exercise on an electric treadmill (5 days/ week, $20 \mathrm{~cm} / \mathrm{s}, 10 \mathrm{~min})$.

\section{Measurement of whole body strength}

Whole body strength was measured weekly using a force transducer coupled to a computer (15). The tail of each mouse was connected through a nonflexible nylon tube to the transducer so that they were electrically stimulated to run, and the force required to pull the cable was continuously recorded. The force values were normalized to the weight of each animal.

\section{Muscle preparation}

After 12 weeks of treatment, a muscle biopsy was carried out on all mdx mice. Samples were collected from the left quadriceps, dissected, frozen in liquid nitrogen, and stored at $-80^{\circ} \mathrm{C}$. Total tissue RNA was extracted with Trizol reagent (Invitrogen Co., USA), according to the manufacturer's instructions, quantified by absorbance at $260 \mathrm{~nm}$, and stored in diethylpyrocarbonate-treated water at $-80^{\circ} \mathrm{C}$. The integrity of RNA was routinely verified by agarose gel electrophoresis. Total RNA ( $2 \mu \mathrm{g})$ was used for first-strand cDNA synthesis (reverse transcriptase) using Moloney murine leukemia virus, and RNaseOUT was also added to protect the RNA during this process).

\section{Quantitative real time polymerase chain reaction}

Gene expression of myostatin, transforming growth factor- $\beta 1$ (TGF- $\beta 1$ ) and tumor necrosis factor- $\alpha$ (TNF- $\alpha$ ) was determined by quantitative real time polymerase chain reaction (qRT-PCR) using SybrGreen Master Mix (Invitrogen). $\beta$-actin was used as an internal control. The reaction was carried out with $1 \mu \mathrm{L}$ diluted cDNA (20 ng), $10 \mu \mathrm{L}$ SybrGreen Master Mix (Invitrogen), $0.5 \mu \mathrm{L}$ forward primer $(10 \mu \mathrm{M}), 0.5 \mu \mathrm{L}$ reverse primer $(10 \mu \mathrm{M})$, and $8 \mu \mathrm{L}$ RNAse-free water in a final volume of $20 \mu \mathrm{L} /$ well. The thermocycle included an initial incubation at $95^{\circ} \mathrm{C}$ for $2 \mathrm{~min}$, followed by 40 cycles of $95^{\circ} \mathrm{C}$ for $15 \mathrm{~s}, 60^{\circ} \mathrm{C}$ for $60 \mathrm{~s}$, and $72^{\circ} \mathrm{C}$ for $15 \mathrm{~s}$. The qRT-PCR was performed in triplicate. The primer sequences and their respective product length are reported in Table 1.

Relative gene expression fold change was calculated using the delta delta $\mathrm{Ct}$ method. The results were subjected to analysis of variance using the GBStat program (England), and $\mathrm{P}<0.05$ was considered to be significant.

\section{Results}

\section{Measurement of whole body strength}

The muscle strength values were appropriate for the weight of the animal. There was no change in strength between the control animals and those treated with rhEPO during the 12 weeks of treatment. The total force of $\mathrm{mdx}$ mice is reported in Figure 1.

\section{qRT-PCR}

In order to determine whether recombinant EPO had an effect on the regeneration process of $\mathrm{mdx}$ dystrophic muscle in mice, we quantified expression of the myostatin gene, TGF- $\beta 1$, and TNF- $\alpha$ by qRT-PCR. After 12 weeks of treatment with rhEPO, there was a significant decrease in myostatin gene expression (Figure 2). There was no difference in TGF- $\beta 1$ and TNF- $\alpha$ gene expression between groups.

\section{Discussion}

This study evaluated the possible beneficial effect of recombinant EPO therapy in the degenerative process of dystrophic muscles in $\mathrm{mdx}$ mice, the most common experimental model used to study DMD (15). We observed no change in strength between the control animals and those treated with rhEPO during the 12 weeks of treatment. Myostatin expression was significantly decreased in quadriceps from $\mathrm{mdx}$ mice treated with rhEPO; however, no significant effect of rhEPO was seen in the expression of TGF- $\beta 1$ and TNF- $\alpha$. 
Table 1. Forward and reverse primers for quantitative real time PCR analyses.

\begin{tabular}{|c|c|c|}
\hline Primer & Sequence & Product length $(\mathrm{pb})$ \\
\hline TGF- $\beta 1$ (accession No. M13177) & & 80 \\
\hline Forward & 5' CCCCACTGATACGCCTGAGT 3' & \\
\hline Reverse & 5' AGCCCTGTATTCCGTCTCCTT 3' & \\
\hline TNF- $\alpha$ (accession No. NM_013693.2) & & 275 \\
\hline Forward & 5' ATGAGCACAGAAAGCATGATC 3' & \\
\hline Reverse & 5' TACAGGCTTGTCACTCGAATT 3' & \\
\hline Myostatin (accession No. NM_010834.2) & & 83 \\
\hline Forward & 5' ACGCTACCACGGAAACAATC 3' & \\
\hline Reverse & 5' AAAGCAACATTTGGGCTTTC 3' & \\
\hline
\end{tabular}

TGF- $\beta 1$ : transforming growth factor beta $1 ;$ TNF- $\alpha$ : tumor necrosis factor alpha.

DMD is the most common lethal genetic disease. Corticosteroids are currently the only available diseasemodifying therapy for DMD, by prolonging independent ambulation and delaying the onset of secondary complications (16). However, the use of chronic high-dose corticosteroids for DMD is frequently associated with significant side effects and does not stop disease progression (16). An effective treatment for DMD requires a combination of therapies, including pharmacological agents, gene therapy, and target cells in an attempt to reach the process pathways involved in muscle degeneration and necrosis (17). EPO has several effects that could aid in the repair of skeletal muscle injury and prevention of fibrosis (1). In mdx mice, we did not observe any increase in muscle strength. An EPO analog, carbamylated EPO, was not demonstrated as an effective therapy for DMD in mdx mice (18).

We assessed the gene expression of cytokines involved in the disease and observed a direct action of the drug in spite of increased muscle oxygen delivery in vitro.

TGF- $\beta 1$ is highly upregulated in dystrophic skeletal muscle (19), and the level of TGF- $\beta 1$ protein is significantly elevated in the mdx diaphragm at 12 weeks of age (20). These cytokines are expressed by inflammatory cells such as macrophages (21) and have been shown to stimulate

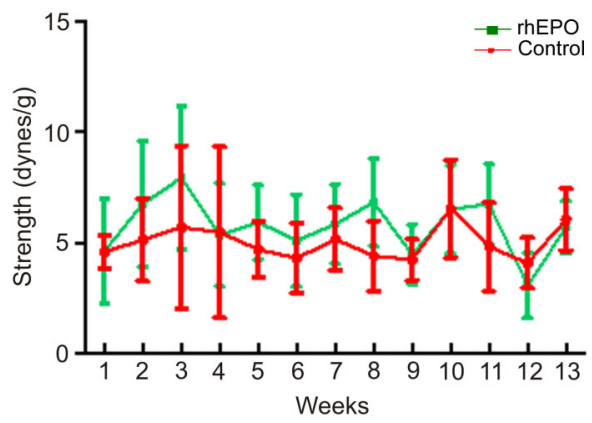

Figure 1. Strength of the entire body of $\mathrm{mdx}$ mice treated with recombinant human erythropoietin (rhEPO) or saline (control) for 12 weeks. $\mathrm{P}>0.05$, GBStat test. collagen synthesis (22). In our experiments, the results of TGF- $\beta 1$ did not show any difference. Perhaps the EPO concentration we used was not able to activate this pathway.

DMD patients have higher serum TNF- $\alpha$ levels, and TNF- $\alpha$-positive fibers have been found by in situ hybridization and immunohistochemistry in muscles of dystrophic DMD subjects (23). Controversial results and muscle type dependent effects have been observed in TNF- $\alpha$ knockout mdx mice; and histopathological analysis has found that the absence of TNF- $\alpha$ in vivo resulted in equivocal findings as opposed to amelioration of muscle pathology as predicted (24), although long-term deletion of TNF- $\alpha$ appeared beneficial in older (12 months) $\mathrm{mdx} / \mathrm{TNF}-\alpha(-/-)$ mice (25). The pharmacological approach using weekly TNF- $\alpha$ antibody during early postnatal life clearly delayed and greatly reduced the breakdown of dystrophic muscle (26). However, no proof of functional benefit of this specific anti-TNF- $\alpha$ therapy has been provided. We did not observe a significant effect of EPO in expression of the TGF gene.

Myostatin, a member of the TGF family, is an important negative regulator of skeletal muscle mass (27). The deletion of the myostatin gene in the $\mathrm{mdx}$ mouse increases not only muscle mass but also muscle strength (as measured by grip strength). Remarkably, histological analysis of the diaphragm, one of the most severely affected muscles in the mdx mouse, showed a reduced dystrophic phenotype in myostatin/mdx double mutants (28). The injection of anti-myostatin monoclonal antibodies into $\mathrm{mdx}$ mice on a weekly basis for a period of 3 months resulted in muscle mass increases up to $35 \%$ in individual muscles after myostatin blockade (29). Conversely, transgenic mice that overexpress myostatin selectively in skeletal muscle have lower muscle mass (30). Finally, these observations indicate that myostatin negatively regulates skeletal muscle mass. For the first time, we report that a significant reduction in myostatin expression in mdx mice treated with rhEPO may signify a new direct mode of action of EPO in skeletal muscle.

The direct actions of EPO in skeletal muscles independent of its action in the hematopoietic system have been 

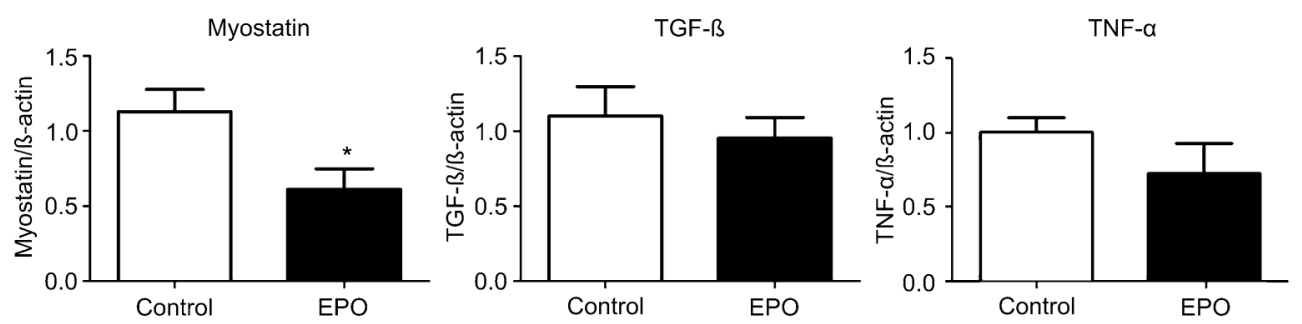

Figure 2. Myostatin, transforming growth factor beta (TGF- $\beta$ ), and tumor necrosis factor alpha (TNF- $\alpha$ ) gene expression in the left quadriceps of treated (EPO) and control mdx mice. ${ }^{*} \mathrm{P}<0.05$, GBStat test.

studied by several authors $(31,32)$. EPO has been described as exerting effects similar to vascular endothelial growth factor (VEGF) on the angiogenic process, and one of the mechanisms by which EPO appears to promote angiogenesis is by enhancing the level of VEGF in tissues. A close association between VEGF and EPO in angiogenesis has been proposed (33), and EPO treatment has been found to enhance the release of VEGF from marrow stromal cells (31) and to increase levels of VEGF in brain (32). Considering the importance of VEGF in skeletal muscle capillary growth (34), it is, therefore, plausible that one of the angiogenic effects of EPO is mediated by promoting VEGF levels in muscle. This effect can explain the decrease in myostatin in our experiments.

Human myoblasts treated with bupivacaine showed a dose-dependent decrease in mitochondrial membrane potential associated with unusual morphologies. Impairment of mitochondrial bioenergetics was prevented partially by the use of rhEPO co-administered with bupivacaine (35).

Another interesting potential physiological role of EPO in skeletal muscle is in muscle fiber growth. Erythropoietin receptor (EPO-R) activation stimulates the signal transducer and activator of transcription 5 (STAT5), which is known to modulate cell proliferation and differentiation (36). STAT5 also activates the phosphoinositide 3 (PI3)-kinaseprotein kinase $B$ (Akt) signaling pathway $(37,38)$, which is believed to result in activation of AKT and p70s6K, which in turn plays a role in transcription and cell cycle progression. This pathway has been suggested to be critical in the

\section{References}

1. Rotter R, Menshykova M, Winkler T, Matziolis G, Stratos I, Schoen $\mathrm{M}$, et al. Erythropoietin improves functional and histological recovery of traumatized skeletal muscle tissue. J Orthop Res 2008; 26: 1618-1626, doi: 10.1002/jor.20692.

2. Lappin TR, Maxwell AP, Johnston PG. EPO's alter ego: erythropoietin has multiple actions. Stem Cells 2002; 20: 485-492, doi: 10.1634/stemcells.20-6-485.

3. Scoppetta C, Grassi F. Erythropoietin: a new tool for muscle disorders? Med Hypotheses 2004; 63: 73-75, doi: 10.1016/ j.mehy.2003.12.044.

4. Ogilvie M, Yu X, Nicolas-Metral V, Pulido SM, Liu C, Ruegg regulation of skeletal muscle hypertrophy (38), On the basis of the above findings, it appears plausible that EPO$\mathrm{R}$ activation may contribute to the regulation of skeletal muscle fiber growth, activating the STAT pathway and downregulating myostatin, as shown in our results.

We can speculate that EPO regulates the expression of various genes. Acute injections of $\operatorname{rhEPO}(15,000 \mathrm{IU})$ did not change mRNA levels of VEGF, hypoxia-inducible factor $1 \alpha$ (HIF-1 $\alpha$ ), insulin-like growth factor, ferroportin, myogenic differentiation 1 (MyoD), and myogen in biopsies obtained 2, 4,6 , and $10 \mathrm{~h}$ after injection of rhEPO, while small inductions of myoglobin, EPO-R, transferrin receptor, and myogenic regulatory factor (MRF4) were observed (39).

In our study, the control group was mdx mice treated with saline, because we wanted to observe the possible beneficial effects of recombinant EPO therapy in the degenerative process of dystrophic muscles. We adopted the same experimental model with mdx mice, as had been reported in a previous study from our group (40).

Studying the muscles of mice with muscular dystrophy, we observed no increase in muscle strength, but we found a significant reduction in myostatin. This result can help to clarify some of the mechanisms of the direct action of EPO on skeletal muscle.

\section{Acknowledgments}

The authors are thankful to the Faculdade de Medicina do ABC and Universidade de São Paulo (ICB) for providing infrastructure for this study.
UT, et al. Erythropoietin stimulates proliferation and interferes with differentiation of myoblasts. J Biol Chem 2000; 275: 39754-39761, doi: 10.1074/jbc.M004999200.

5. Wu H, Lee SH, Gao J, Liu X, Iruela-Arispe ML. Inactivation of erythropoietin leads to defects in cardiac morphogenesis. Development 1999; 126: 3597-3605.

6. Heuberger JA, Cohen Tervaert JM, Schepers FM, Vliegenthart $A D$, Rotmans JI, Daniels JM, et al. Erythropoietin doping in cycling: Lack of evidence for efficacy and a negative riskbenefit. Br J Clin Pharmacol 20112; 1: 100-106.

7. Vaziri ND. Cardiovascular effects of erythropoietin and 
anemia correction. Curr Opin Nephrol Hypertens 2001; 10: 633-637, doi: 10.1097/00041552-200109000-00013.

8. Emery AE. Population frequencies of inherited neuromuscular diseases - a world survey. Neuromuscul Disord 1991; 1: 19-29, doi: 10.1016/0960-8966(91)90039-U.

9. Merlini L, Gennari M, Malaspina E, Cecconi I, Armaroli A, Gnudi S, et al. Early corticosteroid treatment in 4 Duchenne muscular dystrophy patients: 14-year follow-up. Muscle Nerve 2012; 45: 796-802, doi: 10.1002/mus.23272.

10. Jennekens FG, ten Kate LP, de Visser M, Wintzen AR. Diagnostic criteria for Duchenne and Becker muscular dystrophy and myotonic dystrophy. Neuromuscul Disord 1991; 1: 389-391, doi: 10.1016/0960-8966(91)90001-9.

11. McDonald CM, Abresch RT, Carter GT, Fowler WM Jr, Johnson ER, Kilmer DD, et al. Profiles of neuromuscular diseases. Duchenne muscular dystrophy. Am J Phys Med Rehabil 1995; 74: S70-S92, doi: 10.1097/00002060199509001-00003.

12. Passamano L, Taglia A, Palladino A, Viggiano $E$, D'Ambrosio P, Scutifero M, et al. Improvement of survival in Duchenne Muscular Dystrophy: retrospective analysis of 835 patients. Acta Myol 2012; 31: 121-125.

13. Biggar WD, Gingras M, Fehlings DL, Harris VA, Steele CA. Deflazacort treatment of Duchenne muscular dystrophy. $J$ Pediatr 2001; 138: 45-50, doi: 10.1067/mpd.2001.109601.

14. Deconinck N, Dan B. Pathophysiology of duchenne muscular dystrophy: current hypotheses. Pediatr Neurol 2007; 36: 1-7, doi: 10.1016/j.pediatrneurol.2006.09.016.

15. Granchelli JA, Pollina C, Hudecki MS. Pre-clinical screening of drugs using the mdx mouse. Neuromuscul Disord 2000; 10: 235-239, doi: 10.1016/S0960-8966(99)00126-1.

16. Biggar WD, Harris VA, Eliasoph L, Alman B. Long-term benefits of deflazacort treatment for boys with Duchenne muscular dystrophy in their second decade. Neuromuscul Disord 2006; 16: 249-255, doi: 10.1016/j.nmd.2006.01.010.

17. Liew WK, Kang PB. Recent developments in the treatment of Duchenne muscular dystrophy and spinal muscular atrophy. Ther Adv Neurol Disord 2013; 6: 147-160, doi: $10.1177 / 1756285612472386$.

18. Wu MP, Gussoni E. Carbamylated erythropoietin does not alleviate signs of dystrophy in mdx mice. Muscle Nerve 2011; 43: 88-93, doi: 10.1002/mus.21785.

19. Bernasconi $P$, Torchiana E, Confalonieri $P$, Brugnoni $R$, Barresi R, Mora M, et al. Expression of transforming growth factor-beta 1 in dystrophic patient muscles correlates with fibrosis. Pathogenetic role of a fibrogenic cytokine. J Clin Invest 1995; 96: 1137-1144, doi: 10.1172/JCI118101.

20. Hartel JV, Granchelli JA, Hudecki MS, Pollina CM, Gosselin LE. Impact of prednisone on TGF-beta1 and collagen in diaphragm muscle from mdx mice. Muscle Nerve 2001; 24: 428-432, doi: 10.1002/1097-4598(200103)24:3<428::AIDMUS1018>3.0.CO;2-E.

21. Robertson TA, Maley MA, Grounds MD, Papadimitriou JM. The role of macrophages in skeletal muscle regeneration with particular reference to chemotaxis. Exp Cell Res 1993; 207: 321-331, doi: 10.1006/excr.1993.1199.

22. Grande JP, Melder DC, Zinsmeister AR. Modulation of collagen gene expression by cytokines: stimulatory effect of transforming growth factor-beta1, with divergent effects of epidermal growth factor and tumor necrosis factor-alpha on collagen type I and collagen type IV. J Lab Clin Med 1997;
130: 476-486, doi: 10.1016/S0022-2143(97)90124-4

23. Kuru S, Inukai A, Kato T, Liang Y, Kimura S, Sobue G. Expression of tumor necrosis factor-alpha in regenerating muscle fibers in inflammatory and non-inflammatory myopathies. Acta Neuropathol 2003; 105: 217-224.

24. Spencer MJ, Marino MW, Winckler WM. Altered pathological progression of diaphragm and quadriceps muscle in TNFdeficient, dystrophin-deficient mice. Neuromuscul Disord 2000; 10: 612-619, doi: 10.1016/S0960-8966(00)00160-7.

25. Gosselin LE, Barkley JE, Spencer MJ, McCormick KM, Farkas GA. Ventilatory dysfunction in mdx mice: impact of tumor necrosis factor-alpha deletion. Muscle Nerve 2003; 28: 336-343, doi: 10.1002/mus.10431.

26. Grounds MD, Torrisi J. Anti-TNFalpha (Remicade) therapy protects dystrophic skeletal muscle from necrosis. FASEB $J$ 2004; 18: 676-682, doi: 10.1096/fj.03-1024com.

27. Whittemore LA, Song K, Li X, Aghajanian J, Davies M, Girgenrath $S$, et al. Inhibition of myostatin in adult mice increases skeletal muscle mass and strength. Biochem Biophys Res Commun 2003; 300: 965-971, doi: 10.1016/ S0006-291X(02)02953-4.

28. Wagner KR, McPherron AC, Winik N, Lee SJ. Loss of myostatin attenuates severity of muscular dystrophy in $\mathrm{mdx}$ mice. Ann Neurol 2002; 52: 832-836, doi: 10.1002/ana.10385.

29. Bogdanovich S, Krag TO, Barton ER, Morris LD, Whittemore LA, Ahima RS, et al. Functional improvement of dystrophic muscle by myostatin blockade. Nature 2002; 420: 418-421, doi: 10.1038/nature01154.

30. Reisz-Porszasz S, Bhasin S, Artaza JN, Shen R, Sinha-Hikim I, Hogue A, et al. Lower skeletal muscle mass in male transgenic mice with muscle-specific overexpression of myostatin. Am J Physiol Endocrinol Metab 2003; 285: E876E888.

31. Alvarez Arroyo MV, Castilla MA, Gonzalez Pacheco FR, Tan D, Riesco A, Casado S, et al. Role of vascular endothelial growth factor on erythropoietin-related endothelial cell proliferation. J Am Soc Nephrol 1998; 9: 1998-2004.

32. Zhang D, Zhang F, Zhang Y, Gao X, Li C, Ma W, et al. Erythropoietin enhances the angiogenic potency of autologous bone marrow stromal cells in a rat model of myocardial infarction. Cardiology 2007; 108: 228-236, doi: $10.1159 / 000096803$.

33. Li Y, Lu Z, Keogh CL, Yu SP, Wei L. Erythropoietin-induced neurovascular protection, angiogenesis, and cerebral blood flow restoration after focal ischemia in mice. J Cereb Blood Flow Metab 2007; 27: 1043-1054.

34. Prior BM, Lloyd PG, Yang HT, Terjung RL. Exerciseinduced vascular remodeling. Exerc Sport Sci Rev 2003; 31: 26-33, doi: 10.1097/00003677-200301000-00006.

35. Farrell F, Lee A. The erythropoietin receptor and its expression in tumor cells and other tissues. Oncologist 2004; 9 (Suppl 5): 18-30, doi: 10.1634/theoncologist.9-90005-18.

36. Ratajczak J, Majka M, Kijowski J, Baj M, Pan ZK, Marquez LA, et al. Biological significance of MAPK, AKT and JAK-STAT protein activation by various erythropoietic factors in normal human early erythroid cells. Br J Haematol 2001; 115: 195204.

37. Tramontano AF, Muniyappa R, Black AD, Blendea MC, Cohen I, Deng L, et al. Erythropoietin protects cardiac myocytes from hypoxia-induced apoptosis through an 
Akt-dependent pathway. Biochem Biophys Res Commun 2003; 308: 990-994, doi: 10.1016/S0006-291X(03)01503-1.

38. Bodine SC, Stitt TN, Gonzalez M, Kline WO, Stover GL, Bauerlein R, et al. Akt/mTOR pathway is a crucial regulator of skeletal muscle hypertrophy and can prevent muscle atrophy in vivo. Nat Cell Biol 2002; 3: 1014-1019, doi: 10.1038/ ncb1101-1014.

39. Lundby C, Hellsten $Y$, Jensen MB, Munch AS, Pilegaard H.
Erythropoietin receptor in human skeletal muscle and the effects of acute and long-term injections with recombinant human erythropoietin on the skeletal muscle. J Appl Physiol 2008; 104: 1154-1160.

40. Feder D, Rodrigues BG, I, Guimaraes Pereira ML, Silva CS, Nogueira SD, Fonseca FL, et al. Hormonal receptors in skeletal muscles of dystrophic mdx mice. Biomed Res Int 2013; 2013: 604635, doi: 10.1155/2013/604635. 